\title{
Meeting the demand for skilled precision engineers
}

\author{
Chris Sansom and Paul Shore \\ Precision Engineering Centre, Cranfield University, Cranfield, UK
}

\begin{abstract}
Purpose - This paper demonstrates how science and engineering graduates can be recruited and trained to Masters level in precision engineering as an aid to reducing the skills shortage of mechanical engineers in UK industry.

Design/methodology/approach - The paper describes a partnership between three UK academic institutions and industry, creating an Integrated Knowledge Centre (IKC) in Ultra Precision Structured Surfaces. Within this project sits a Knowledge Transfer activity that seeks to channel graduate scientists and engineers through an MSc in "Ultra Precision Technologies" into UK engineering industry. The creation and implementation of this pipeline, its systems and its processes, is the subject of this paper and its case study. Findings - In order to recruit graduate scientists and engineers a proactive model is presented. An Open Systems model of the pipeline process is derived, and the elements within the system are discussed. Implementation difficulties are also explained, with suggestions for further work.
\end{abstract}

Research limitations/implications - The paper describes only the early stages of implementation, and further work is necessary. However, there are important lessons to be learned from the early phases of the project which have implications for postgraduate education and UK manufacturing industry.

Practical implications - The systems model and case studies provide a framework and detail that is of immediate benefit to manufacturing industries and Higher Education establishments.

Originality/value - The originality of the approach lies in the level of integration between the sub-systems that comprise the Open system, within which students and skills are forged together in a programme to produce employable engineering postgraduates. Keywords - Engineering, Postgraduate, United Kingdom, Industry, Knowledge Transfer Paper type - Case Study 
'That's the reasons they're called lessons,' the Gryphon remarked: 'because they lessen from day to day.' (Carroll, 1865).

\section{Introduction}

In order to retain competitive advantage the UK engineering sector requires a regular influx of new talent. The demand for new engineers with the knowledge, creativity, and personal skills to make significant contributions to engineering issues in a commercial environment has never been greater. However the pipeline process to supply high quality engineers is both dynamic and complex. This paper looks at the problems perceived by the UK precision engineering sector in recruiting high-calibre graduates, the issues involved, discusses methods and processes to minimize the mismatch between students' aspirations and companies' requirements, and discusses a case study reflecting an initiative to minimise the mismatch.

\section{Problem definition}

Despite the pressure from global competition the UK precision engineering industry continues to thrive, and is a key enabling force in a range of modern technology rich applications. These include space, aerospace, optics, optoelectronics, machine tools, energy generation (both nuclear fusion and alternative renewable sources), sensors, displays, and medical. Products can range from prosthetic joints through wind turbines to mirror segments for space and ground-based telescopes. The common need for all of these applications is a skilled and effective pool of graduate precision engineers, mainly with a mechanical bias.

In 1995, the Daily Telegraph wrote,

"Britain may have many assets; its people are not....among them. We are too old, we are poorly educated and our attitude is appalling. Our inadequate educational system ranks $35^{\text {th }}$ (in the world), there is little motivation to retrain for new jobs, and we lack competitive values such as hard work, tenacity and loyalty. Britain also ranks badly for both gender and race equality. Women in Turkey, Egypt and Colombia have better career prospects...." 
This was a popular view of the industrial workforce in the previous decade and, unless moderated in the interim, will be a popular view of decision makers within UK industry today. This view of an inflexible, poorly educated and uncommitted workforce has been a factor in erecting a barrier between employers and prospective employees. At the graduate recruitment level this view may be less prevalent, but there are other causes affecting the employability of graduates in UK industry (Rae, 2007). At the supply end of the recruitment pipeline, there are problems connected specifically to "engineering as a career", as shown in the UK HE statistics (HESA, 2005/6). Figure 1 compares the number

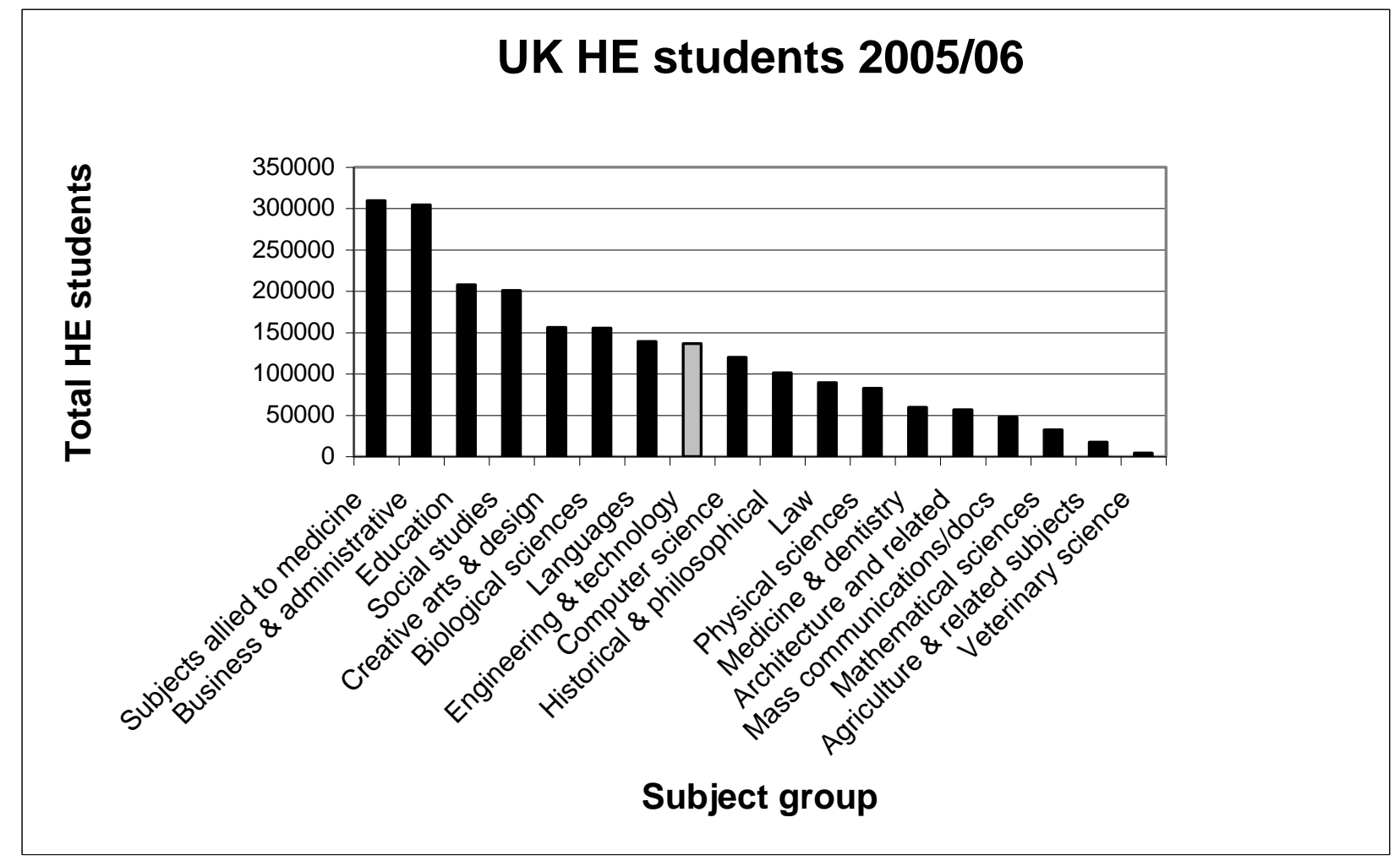

Figure 1 . UK HE students by subject group (HESA, 2005/6)

of students studying Engineering and Technology courses with other subject groups, and demonstrates the competition for students. Figure 2 demonstrates that Engineering \& Technology fare better at Postgraduate level, especially given the high proportion $(>60 \%)$ of part-time students in the Education and Business \& Administrative categories. However, only $10 \%$ of Postgraduate Engineering \& Technology students are to be found in the Mechanical Engineering field of study, 


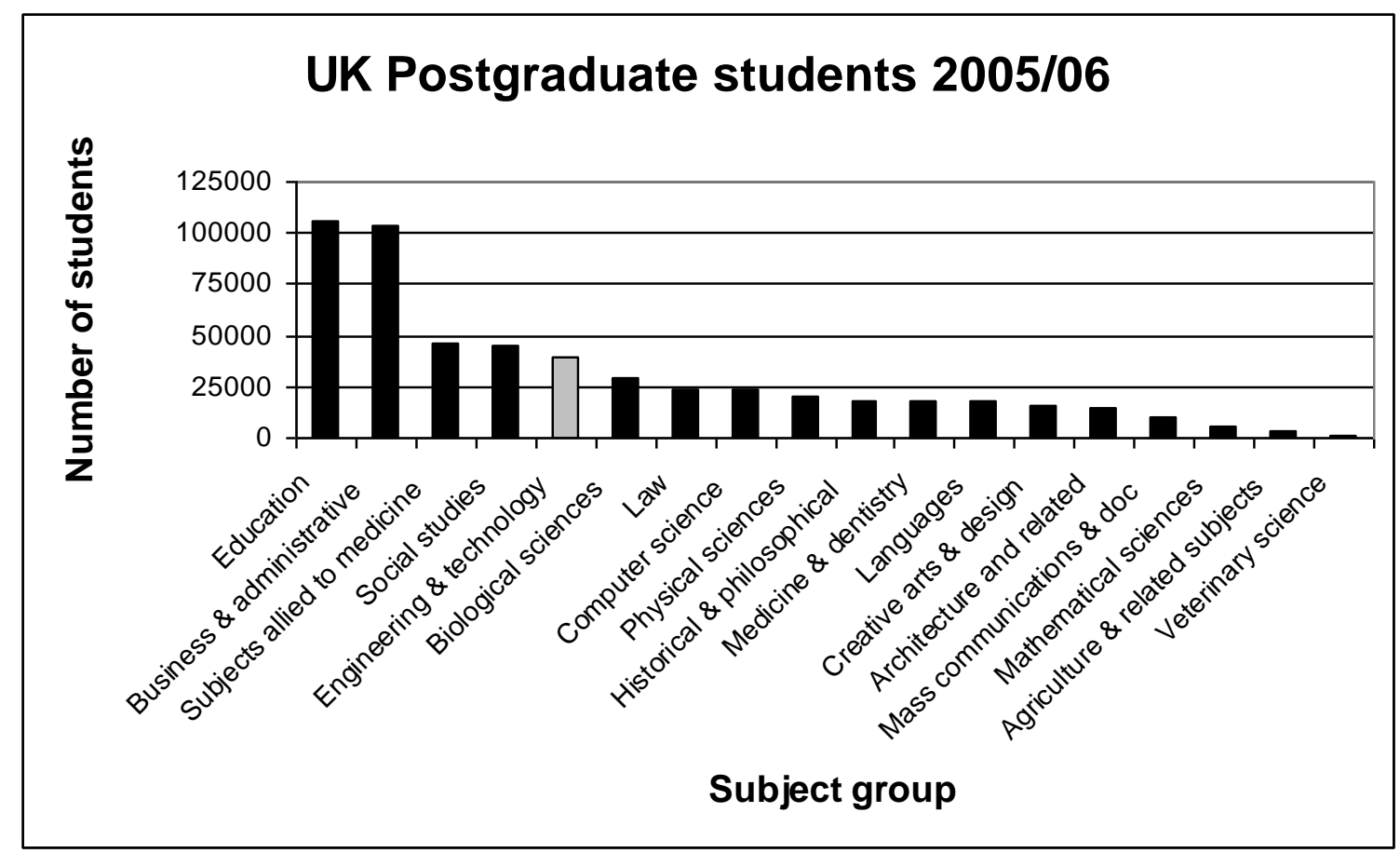

Figure 2. UK Postgraduate students by subject group (HESA, 2005/6)

emphasising the strong competition from electronic, civil, and general engineering taught courses and research opportunities.

The figures also conceal a gender bias within engineering. In UK HE women account for only $15.8 \%$ of the total students studying Engineering \& Technology subjects. For mechanical engineering this percentage falls to 8.5\% (HESA,2005/6). There is also research to show that only $28 \%$ of women who train as engineers emerge to take up employment as a professional engineer thereafter (Setwomenstats, 2004/5). It is clear that if we wish to deliver a stream of high-quality employment-ready mechanicallybiased engineers into precision technology hungry industrial environments we must market our postgraduate courses and provide learning experiences that meet the aspirations of both male and female students.

In terms of course design, there is also the need to consider the life and work experience of students. Particularly at the postgraduate level, the age and experience span of a typical cohort can be quite broad. This includes those between the ages of 35 and 55 which (Rae,2005) calls mid-career entrepreneurs or MCEs, and those in the final phase or their working lives (Blackburn and Mackintosh, 1999). Both of these groups, finding 
themselves making a career change through choice or necessity, can bolster the supply of precision engineers - provided that their previous knowledge and experience, their learning capabilities, their aspirations and support needs are designed into the training package. With an aging population and the likelihood that working life will be extended as life expectancy increases, the probability of a mid-career change increases. One further issue is pertinent to a discussion of course design and student intake. UK (Home) students account for only $34 \%$ of the total number studying postgraduate courses (HESA, 2005/6), not including PhD, PGCE. If one of our major goals is the recruitment, education, and retention of precision engineering talent for the benefit of UK manufacturing industry we must ensure that the lack of home-based students is also addressed (but not to the detriment of the reputation of UK HE establishments as pre-eminent in the education of EU and Overseas students).

\section{Systems description}

The lack of any formal connection between Higher Education and business has been well documented (Yasin et al, 2000). This situation persisted throughout the latter half of the last century, and can be modelled as a set of closed systems. The two primary systems of interest are the business (industrial engineering employer) system and the teaching and learning system (postgraduate level Masters in the context of this research). These, with the main

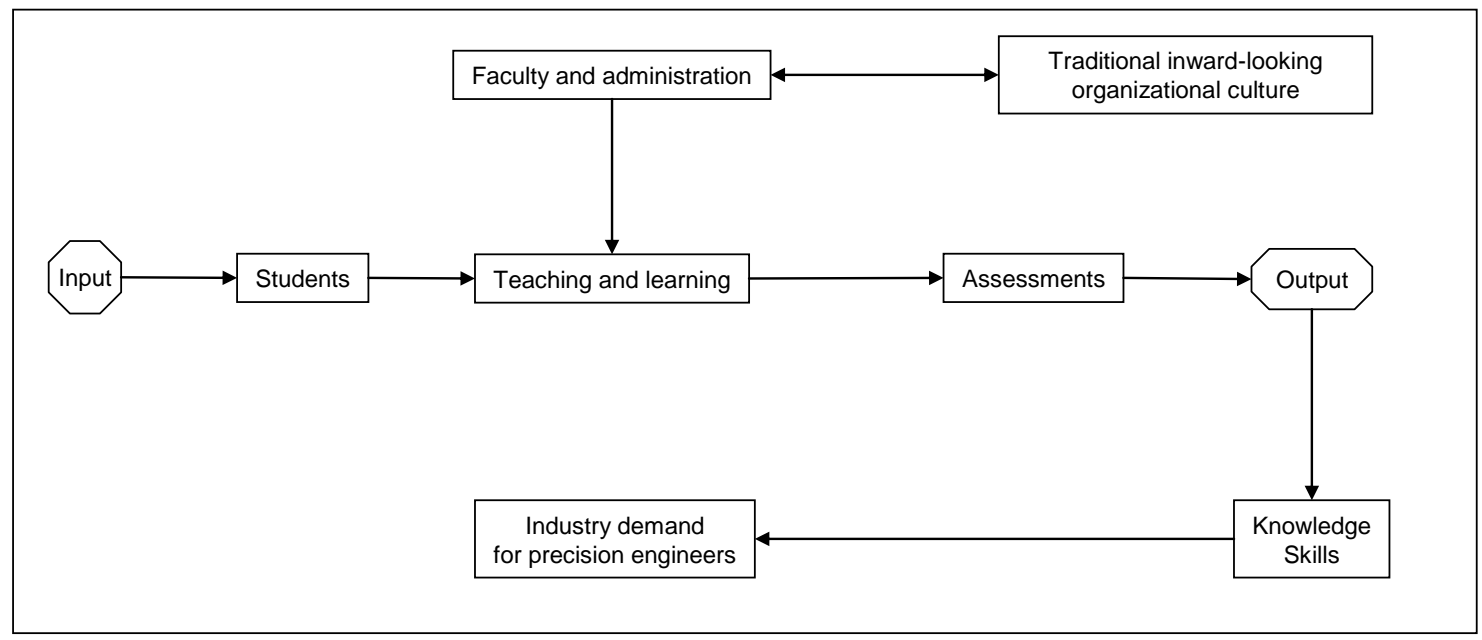

Figure 3 : Traditional teaching showing the elements of a closed system (after Yasin et al. , 2000). 
sub-systems and process elements of interest are shown in Figure 3. The systems show little connectivity and exhibit no effective feed forward or feedback control mechanism. Course design and development occur as a top-down implementation of HE establishment strategy, embedded within an inward-facing culture. The end-customers (industrial employers) are the recipients of an output that they have little opportunity to influence. The teaching staff, students, and employers are alienated in this arrangement. The HE institution may find it hard to attract high quality students as the employability of the postgraduates that emerge from the teaching and learning processes is likely to a matter of good fortune. UK students are likely to emerge from their first degree with financial debts, owing to increasing undergraduate fees and lower grants. Faced with increased choice of postgraduate opportunities, a Masters degree is not a choice to be taken lightly. In this buyers market, the HE institution must adjust its processes to ensure much closer alignment with the needs of today's engineering students and the business environment that demands their knowledge, skills, experience, and emotional intelligence.

This implies the adoption of an open systems approach. The system must include a high level of integration between the system's components, in particular a partnership between the HE institution and the employer. Figure 4 shows an open systems model which is

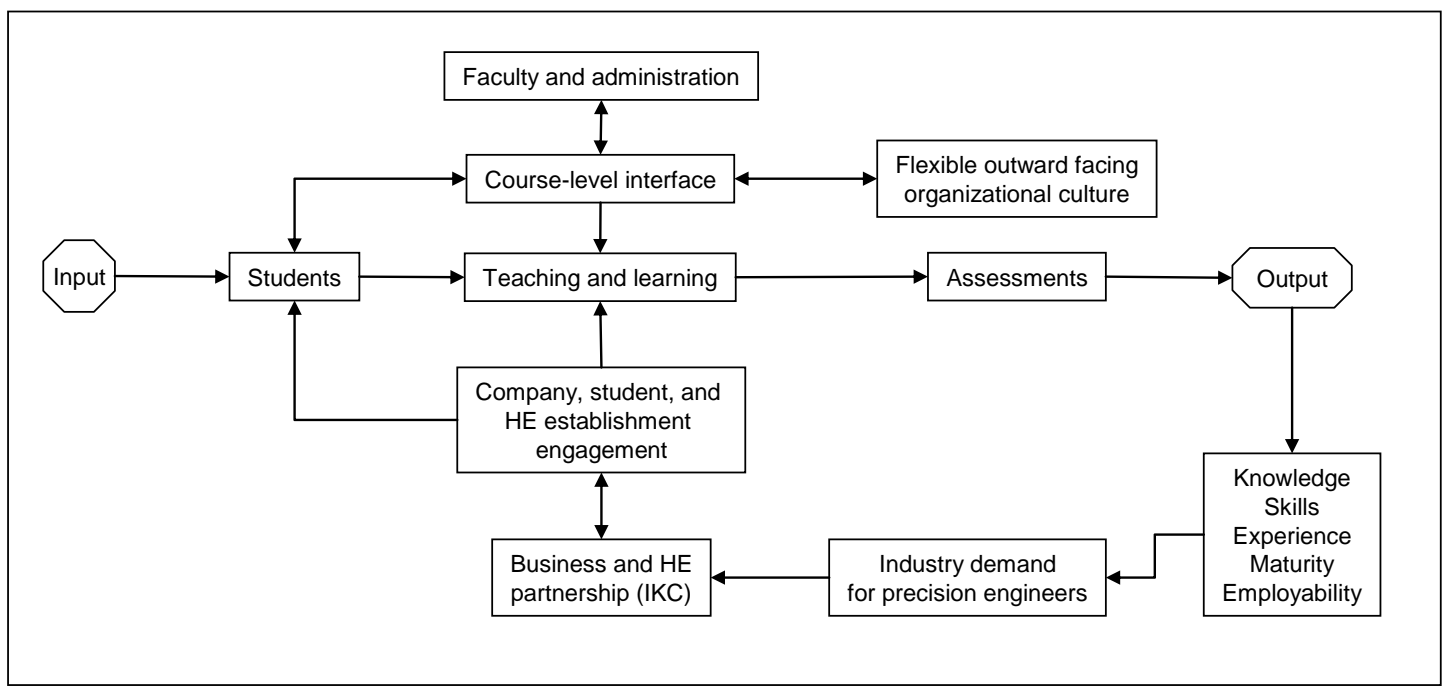

Figure 4: Open systems model emphasizing company-student engagement 
based on the work of (Yasin et al, 2000), but extended to meet the special requirements of UK precision engineering clients. In particular, there is a need for greater engagement between students and employers at all stages in the recruitment and learning processes. This is met by the inclusion of an intermediate shell of sub-processes which provide a proactive link between individual students and company representatives. These are described as the "Course level interface" and "Company, student, and HE establishment engagement" sub-systems in Figure 4, and are the domain of a dedicated HE academic or professional.

In this model the student is pulled into the teaching and learning sub-system by these "shell" processes which act in addition to the existing HE marketing and promotional activities. Interaction with potential employers takes place prior to course registration, and as part of the recruitment process. This link becomes stronger as the Masters course progresses, with Company placements and sponsorships available to the most able students. Each participating Company becomes a key stakeholder in the overall system, with interest in student recruitment, the course content, project work, and assessment criteria. The shell processes are intended to collect and process the outputs from the student and company experiences in order to enhance both the teaching process and the design of the overall system. As described later, the benefits of the proactive engagement between the HE establishment, UK engineering employers, and the prospective postgraduate student are reflected in the percentage intake of UK students and female applicants to the Cranfield University MSc in "Ultra Precision Technologies".

\section{The Integrated Knowledge Centre (IKC) in Precision Engineering}

Joint ventures between educational institutions and companies have been created in a number of fields, including mechanical engineering (Kettunen, 2006). In the context of UK precision engineering this top-level platform is provided by a unique partnership between UK academia and industry, the UPS ${ }^{2}$ Integrated Knowledge Centre (IKC).

The Ultra Precision and Structured Surfaces Integrated Knowledge Centre (UPS ${ }^{2}$ ) was initiated in January 2007 through an EPSRC "pilot" call. IKCs are intended to 
develop new approaches to support UK industry through a wide range of industry-facing technology transfer and innovation initiatives. A key demand in establishing IKCs was that they focus on wealth creation activities and as such they should themselves become "self supporting after the initial 5 year EPSRC funding period".

The mission of UPS ${ }^{2}$ is to establish a world-leading Centre of Excellence that delivers to UK industry 'disruptive' technologies enabling the development and manufacture of a wide range of next generation products which are dependent on functional ultra precision and structured surfaces.

UPS $^{2}$ is a unique centre based around established partnerships between Cranfield University, University College London and University of Cambridge, together with the Technium OpTIC. UPS ${ }^{2}$ is located at the Technium Optic (OpTIC) amongst the companies forming the significant North Wales opto-electronics business cluster. OpTIC is itself a dedicated knowledge transfer and business incubator centre and is therefore an ideal location for establishing an industry-facing knowledge transfer and innovation initiative on behalf of EPSRC.

$\mathrm{UPS}^{2}$ is concerned with the manufacturing technologies relating to ultra precision and structured surfaces as applied to many next generation products. Such surfaces are applied within products across a wide spectrum of markets including: optoelectronics and displays, medical devices, aerospace, defence, space and automotive sectors. These sectors represent over $£ 75$ billion annual business in the UK and account for a major percentage of UK export trade. UPS ${ }^{2}$ therefore provides support for the design and manufacture of UK products having a competitive edge, which is achieved through the application of ultra precision and structured surfaces.

Success will be identified as a self-funding UK Centre of Excellence housed at the Technium OpTIC. It will have world class research facilities with a vibrant research and IP portfolio, supporting the introduction of new UK products. It will operate innovative technology transfer initiatives which support the competitiveness of the UK companies which it serves. In international terms the IKC will be recognized as the leading Centre of Excellence for the development of value adding surface technologies, components and high value products. Furthermore, it will support engagement of UK industry into large scale science programmes that demand ultra precision technologies. The Management 


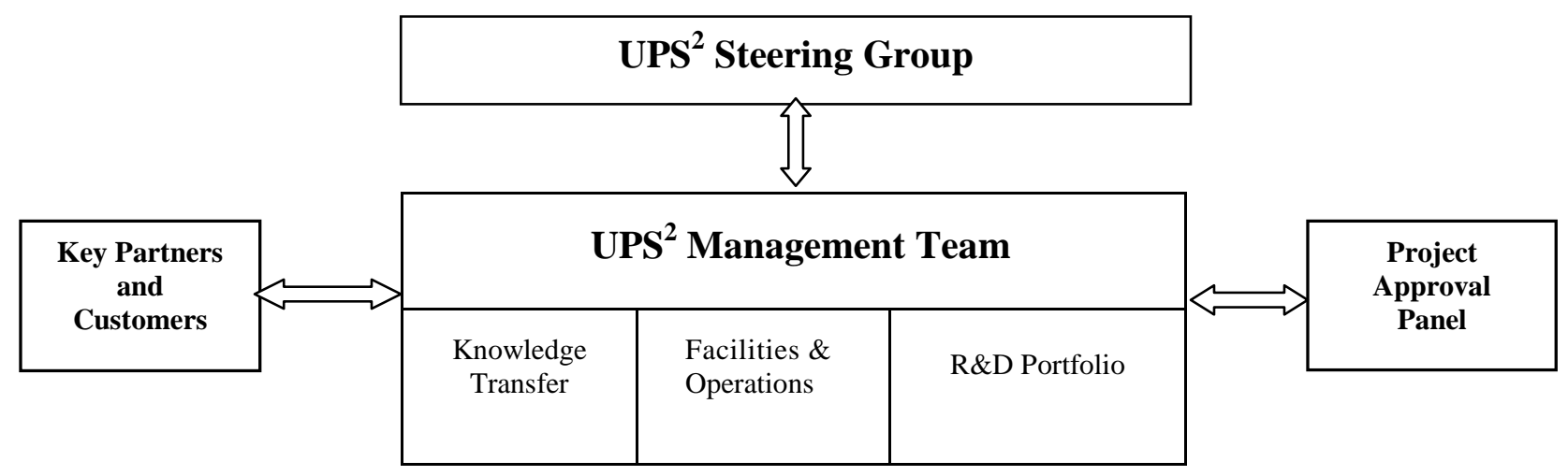

Figure 5: UPS ${ }^{2}$ IKC Management structure

structure of the UPS ${ }^{2}$ IKC is shown schematically in Figure 5. It is important to emphasise the depth of the interactions between the academic partners and the participating companies. Although it is the knowledge transfer activities that are of most interest in the context of this paper, there is an opportunity for a precision engineering partner to link through facilities, equipment, and R\&D too. Within the Knowledge Transfer programme the MSc course is supplemented by industrial short courses, whilst developing e-learning packages for the future. It is the Knowledge Transfer sub-system that includes the processes that provide the important intermediate shell of sub-processes that are shown in Figure 4.

\section{Practical implementation}

\section{Course design}

One key objective is to present UK industry with precision engineers possessing not only the appropriate technical skills at a high level but also the soft personal skills that enhance employability. According to the "DOTS" model, which is based on the QAA (2001) Code of Practice, these skills include (Rae, 2007):
(a) Self-awareness
(b) Opportunity awareness
(c) Decision making 


\section{(d) Transition learning}

Women are attracted to engineering, but their experience in HE discourages them from pursuing that career path (Powell et al., 2004). This is a different problem from one of recruitment into postgraduate education, and is indicative of a gender bias within the internal content and culture of the course. This being the case, it is an issue that we can affect within course design. Two factors that we can incorporate directly into the teaching strategy involve the female preferences for hands-on learning (Madhill et al., 2003) and elements of management (Srivastava, 1996). Also, in order to encourage female engineers to continue beyond the end of the course, a company placement for the individual Masters project is included.

The MSc in "Ultra Precision Technologies" is divided into three components:-

(i) A taught component, given as a series of one-week modules and including lectures, tutorials, case studies, laboratory demonstrations, workshops and exercises as appropriate. These are summarised in Table 1.

(ii) A group project, in which groups of typically 3 - 5 students work as a team on a multi-disciplinary problem of industrial relevance. The project has a strong practical bias, preferably with a hardware output, and can attract commercial sponsorship. In addition to practising precision engineering skills the students also have the opportunity to experience project management and team working, two important qualities on the path to achieving enhanced employability.

(iii) An individual research project of industrial relevance.

For full-time students, the three components are weighted for assessment purposes as follows:

Lecture courses (40\%), Group project (20\%), Individual project (40\%). 
Precision engineering - 'principles and state of the art concepts'

Metrology and optical testing

Managing innovation and new product development

Computer-aided engineering for ultra precision

Optical design and fabrication

Surface engineering and coatings

Modern optical technologies

Laser micromachining and surface structuring

Table 1: Taught modules - MSc in "Ultra Precision Technologies"

The taught modules vary in style from traditional lectures for subject based learning, through experiential learning, to practical sessions with an emphasis on problem based learning. Examples of problem based learning can be found throughout sections of the "Managing innovation and new product development" module, whilst experiential learning predominates in the "Computer-aided engineering for ultra precision" module. It is the difference in presentation and teaching styles that is designed to address the need for different learning styles, in an attempt to reduce gender bias and increase appeal to mid-career change applicants. As discussed by Rae (2005), entrepreneurial learning can aid the mid-career change applicant by facilitating a successful transition from a role that utilises existing skills and expertise to a new role in a field that utilises newly learned skills and expertise. In making the transition to Precision Engineering, an MCE may not have the same recollection of basic science and engineering knowledge as a new graduate. This can be addressed during the Induction week, and in tutorials during the taught modules. Group Project work presents both opportunities and issues for the MCE. Care is needed to ensure that the MCE is not cast as an outsider within a team of new graduates. Rather, the MCE should be given the opportunity to use their experience of problem solving and common-sense solutions to the good of the team. This can be a fine 
balance, and a skilled project facilitator may be needed at key decision points within the duration of the project.

\section{Course marketing}

The Open Systems model of Figure 4 includes sub-systems that reflect the promotion and marketing of the MSc in "Ultra Precision Technologies". In particular, the course level interface and the company/ student engagement processes are key components to reach out to students from the appropriate background that have the potential to graduate at Masters level and be employable in UK Industry. These sub-systems and processes are described in the next section. However there is another high-level system to consider, at the University Faculty or School level. For this system to be effective in promoting and advertising the course, a high degree of organizational flexibility is demanded. This is not to be found in the traditional inward-facing model of Figure 3.

The practical realization of this flexibility is a far from trivial objective. In the ultimate case it would mean the customisation of central marketing activities to the extent that each course would be marketed individually - in a drive towards optimisation. This is clearly impractical, and is also more the aim of the intermediate course-specific processes described in the following section. Hence there is a practical limit, a function of the available resources, which limits the degree of customization. In our work, we received much assistance from the marketing team within the Cranfield University School of Applied Sciences. This manifested itself in the content, VI (Visual Identity), and destination of promotional and marketing collateral. This material was used widely, including the recruitment process described in the next section.

\section{Student recruitment}

The challenge was to recruit science and engineering graduates onto the Cranfield University led (UPS ${ }^{2}$ framed) MSc in "Ultra Precision Technologies". In parallel with the output of the central marketing activities the model of Figure 4 demands a closer interaction with prospective students. The approach taken was to choose two recruitment agencies to convey the course details and benefits to potential students. The use of recruitment agents or consultants reflects the fact that new graduates are more job- 
focused than in previous generations, driven by the need to repay student loans. In addition, engineers seeking a mid-career change plus the generally disenchanted are naturally drawn to recruitment agencies. The brief included the requirement to explain the hands-on nature of the learning experience and the inclusion of a taught module on the management of innovation - both reported in the literature as being important to female students in HE (Madhill et al., 2003) and (Srivastava, 1996).

The results of the recruitment process, which took place over an accelerated period of 10 weeks between July - September 2007, yielded 10 students who started the full-time MSc in "Ultra Precision Technologies" at Cranfield University. Of these, eight were "Home" students, with one "EU" and one "Overseas", as defined by UK HE regulations. Although the statistics are small the achievement of $80 \%$ "Home" students is extremely encouraging, given the fact that the percentage of "Home" students on postgraduate courses (except PhD, PGCE) at all UK HE institutions is 34\%. The situation regarding female students is also promising. 30\% of the October 2007 cohort were female, which compares favourably with the $8.5 \%$ women who study mechanical engineering at HE level (this statistic includes undergraduate plus postgraduate, excluding PhD and PGCE).

The reasons for selecting the course, as given by the students shortly after the Induction week, give an insight into the effectiveness of the recruitment process (see Table 2 below). The Table gives the ten most important factors, as identified in a questionnaire, according to the students. The reputation of Cranfield University in technology subjects is a major factor, together with the involvement of University College London, the University of Cambridge, and OpTIC. Company involvement also scores highly, in the guise of enhanced employability plus company placements for projects and financial support. It is also encouraging to note that the students have realized that the course is intended to attract people with a range of first degree backgrounds, and that there is scope not only for employment but also higher level research on completion of the Masters degree. Other factors scoring highly demonstrate effective communication during the recruitment process. This reflects well on the central Marketing activity within the University, and is also a feature of the intermediate shell process of Figure 4. 


\begin{tabular}{|l|c|}
\hline \multicolumn{1}{|c|}{ Factor } & $\begin{array}{c}\text { Relative } \\
\text { Score }\end{array}$ \\
\hline Cranfield University has a good reputation for technology & 24 \\
\hline Attendance at MSc Selection (Company matching) day & 23 \\
\hline This course caters for people with a range of first degree subjects & 22 \\
\hline Possibility of staying on to do research (PhD) at Cranfield & 21 \\
\hline Information from website, brochures, University staff & 21 \\
\hline Student bursaries and Company sponsorship & 20 \\
\hline Increased chance of employment at the end of the course & 19 \\
\hline Ultra Precision technology covers many applications and products & 17 \\
\hline I discussed the course with a friend/colleague/family member & 17 \\
\hline Additional involvement of UCL, OpTIC, University of Cambridge & 16 \\
\hline
\end{tabular}

Table 2: Reasons for Course selection

Other comments made by the students at the end of the questionnaire mention the ambition to find a more fulfilling role in engineering, or the more general ambition to make a career change. It is also interesting to note the qualifications of applicants, at the time of application. By emphasizing the practical nature of the learning experience, and the opportunity for enhanced employability, students with both Masters degrees and $\mathrm{PhDs}$ applied. As further evidence for the credibility of the course as a retraining medium the applicants also possessed a first degree in a range of subjects. These included the expected subjects of mechanical engineering and physics, but also students with qualifications in electronics, chemistry, medical devices, and nuclear technology.

\section{Company engagement and student sponsorship}


Our challenge is to provide technically competent and emotionally employable precision engineers into UK industry. However, each industrial site will have a different culture and we cannot serve the multiple requirements of technical competence, employability, and organizational readiness unless we individually prepare students for the experience of working in a specific Company. Many authors have discussed the difficult transition between higher education and the workplace, including (Heinz, 1999) and (Arnold and Mackenzie Davey, 1992). In addition (Holden and Hamblett, 2007) extracted three themes from interviews with students after their personal transitions from higher education into UK industry and commerce. These themes reflected the students need to learn the technical aspects of the role, but also to learn to function in an organization and to learn or develop the appropriate personal and emotional skills to be an effective member of that organization. The latter two themes, which were identified as vital to a successful transition by the students themselves, explain why company placements play such a key part in the MSc in Ultra Precision Technologies. By undertaking a Masters level project in a company, the student practices the technical skills that have been learned during the taught courses - but also has to adapt to working within organizational constraints whilst developing the inter-personal skills that will help to ensure an effective contribution. The taught courses are also marketed as stand-alone short courses, providing the students with additional exposure to industrial delegates. The Group project, although located at Cranfield University, also has a role to play in this. It provides a "safe" environment within which to experience (perhaps for the first time) the "forming and storming" stages of a team of diverse individuals. For this reason the Induction week (the first week of the Masters course) includes a session to determine and appreciate each student's Belbin team role.

During the course design stage a number of Companies were approached to participate in the Company placement scheme. This involves the student spending an appropriate length of time on the Company's premises during the Individual Project phase of the Masters degree. This is an important feature of the MSc in Ultra Precision Technologies, carrying $40 \%$ of the total marks, and has a typical duration of between 4-5 calendar months. As illustrated in Figure 4 there is a close relationship between the IKC in Ultra Precision and structures surfaces, the MSc in Ultra Precision Technologies, and 
the participating companies. Indeed the majority of the participating companies had some previous involvement with $\mathrm{UPS}^{2}$ and some were sited amongst the North Wales optoelectronics business cluster. At an early stage it was decided to locate an appropriate number of students in close proximity to the cluster.

Choosing to base a group of students within the North Wales opto-electronics cluster had wide-ranging implications. The major benefits were to the nearby Companies, but there were financial and regulatory issues for the University. These were anticipated however, and were included in Figure 4 under the heading of a "flexible outward facing organizational culture" within the University. Firstly, the UPS ${ }^{2}$ facilities at OpTIC provided office and laboratory facilities for the Wales-based students. Local accommodation was readily available in the form of rented housing, and there are good financial arguments for the purchase and conversion of a property into a student hall of residence as the scheme progresses into future years. Further flexibility from the University faculty was evident in establishing new processes to allow student examinations to be held simultaneously at Cranfield University and OpTIC, a decision that required considerable planning to ensure the rules and regulations of the University were upheld. As in all such matters, quality control and the integrity of the assessment process could not be compromised.

Matching of the student to an Individual Company was a selective and iterative process, once again portraying the close relationships between the Company, the University, the IKC, and the student - as drawn schematically in Figure 4. One month prior to the start of the academic year a "Selection Event" was held, a preliminary step in the process to match students to Companies for the purposes of the Individual project. The event was very well attended by both invited Companies and prospective students. During the day, which included tours and presentations, students were interviewed by the industrialists in order to assess their suitability for project work. Great care was taken to align the wishes of Companies to the expectations of students. Since there were more students than participating companies in the first year of the course the remaining students were allocated projects within the Cranfield University Precision Engineering Centre.

\section{Student assessment}


As mentioned in the previous section, basing the students at two locations, around two hundred miles apart, presented some logistical problems. These required a flexible response from the Faculty, which was forthcoming once the benefits and additional costs had been explored.

However there is the wider issue of how to assess students and gauge their technical learning, their capability of working in an industrial engineering role, and their emotional intelligence - all contributory factors to employability. The industrial experience that the students gain during their Individual projects is widely reported as being the best preparation a student can have (Brown, (1996) and Yasin et al, (2000)). However, we also have to assess the taught elements of the course, only a fraction of which can be tested in the Group and Individual projects. Also, we must ensure that the students are correctly assessed from a quality point of view, namely that they have achieved the Masters level required for graduation from a UK University. As a set of broad principles we have set out to assess technical learning from the taught course modules, industrial engineering capability and the application of technical learning through the Individual Project, and emotional intelligence during both Group and Individual Projects.

The eight taught modules listed in Table 1 employ more than one teaching style, ranging from traditional lectures and tutorials through computer-based packaged learning to business simulations and role playing. A deliberate attempt was made to mix problembased learning and subject-based learning, to cater for the diverse student population. The assessment strategies reflect this, with a mixture of closed book examinations, written assignments and reports, and software models.

The Group project is assessed by means of a written report and an oral presentation. As well as testing the application of technical learning we should remember that the Group Project is also designed to examine the student's ability to work with colleagues in a simulated work-team, and also to observe interpersonal maturity. The main issue in assessing Group projects is to extract an individual mark that reflects the student's contribution. In parallel with the traditional methods of supervisory marking, we have designed a blind and holistic peer review process (Russell et al., 2006) to that end. The results of this will be presented in a later paper. 
The individual project accounts for $40 \%$ of the overall Masters degree in "Ultra Precision Technologies", and is based around a written thesis. Marks are allocated for project approach, execution, and presentation (both written and oral). However since the Individual Project is company based, it is also designed to enhance employability and the ability to work effectively in an industrial engineering role. This is not currently assessed directly, and further work is needed to develop a framework to achieve this.

\section{Conclusions}

In order to retain competitive advantage, UK precision engineering industry requires a regular supply of technically proficient and organizationally prepared graduates. This paper has explained the approach taken at Cranfield University to increase the size of the pool of postgraduate precision engineers. The approach involves the design of a multilevel system, which draws on increased connectivity between the University, UK Engineering companies, and the student. The main vehicle for providing the technical training is the postgraduate Masters degree in "Ultra Precision Technologies". We have explained how this course has been designed for broad appeal, whilst incorporating world class technical teaching and an external focus on the needs of participating companies. Implementation is described in the first year of study, and includes an analysis of the recruitment and company placement processes.

The key lessons to be learned from our case study have relevance to a wider field. Academic institutions need to exhibit the appropriate flexibility to meet the demands of industry and the aspirations of the student. Unless the systems of student recruitment, course delivery, and course content are efficiently aligned, the output of the course will be sub-optimal. At best, these systems should be integrated with industrial partners who become stakeholders to the extent of playing a key role in adjusting the content of the course. Also, course designers need to take advantage of the opportunities to attract midcareer entrants, male and female applicants where there is a notable gender bias, and more home (UK) students where UK demand currently exceeds supply. This is achievable by meticulous planning of course content, course structure and duration, teaching and learning style, assessment strategies, project work and company involvement. For students who face a sometimes bewildering number of postgraduate 
opportunities, it is unsurprising that recruitment is dependent upon the level of engagement with the course team during the application and registration processes. The challenge here is to develop processes that allocate resources in the most efficient manner, bearing in mind that it is the personal contact that the students most cherish, particularly from academic staff. Finally, much can be gained from partnerships between Universities to plug a particular skills gap at the postgraduate level. However, this is likely to bring increased costs which must be recouped as part of an overall strategic plan - for example the sale of industrial short courses and distance learning packages.

Future work will enable us to analyse a larger sample of students and Companies. There will also be a need to flex the fledging systems and processes in response to the demographic and economic changes in the sector. For example the proportion of the population in the 35-55 age group is growing faster than the 16-34 age group. In fact the number of 18 -year-olds in the UK is predicted to fall by $15 \%$ within a decade (Times Higher Education, 2008). This will put greater emphasis on the recruitment of mid-career students, and will require additional support and encouragement to enable mid-career women to develop their potential in engineering (Moore and Buttner, 1997).

\section{Acknowledgements}

The authors wish to acknowledge the help of their colleagues in the development of this research. In particular we would like to recognise the part played in course planning, design and structure by Professor John Corbett and Professor David Allen. Special thanks are also due to the MSc Course Module coordinators and to Cranfield University School of Applied Sciences Marketing team.

\section{References}


Arnold, J.A. and Mackenzie Davey, K. (1992), "Beyond unmet expectations: a detailed analysis of graduate experiences during the first three years of their career", Personnel Review, Vol. 21 No. 2, pp. 45-68.

Blackburn, R. and Mackintosh, L (1999), “The entrepreneurship potential of people in the third age: a case of over expectation?", paper presented at the Small Business and Enterprise Development Conference, University of Leeds, Leeds, March 1999.

Brown, A.E. (1996), "Communication as the common ground between engineering education and industry”, Proceedings of the ASEE 1996 College Industry Education Conference, pp. 101-2.

Carroll, L. (1865), Alice's Adventures in Wonderland.

HESA (Higher Education Statistics Agency), Students and Qualifiers Data Tables 2005/6, www.hesa.ac.uk.

Heinz, W.R. (1999), From Education to Work, Cambridge University Press, Cambridge, MA

Holden,R. and Hamblett,J (2007), "The transition from higher education into work: tales of cohesion and fragmentation”, Education + Training, Vol. 49 No. 7, pp. 516-585.

Kettunen, J. (2006), "Strategies for the cooperation of educational institutions and companies in mechanical engineering", International Journal of Educational Management, Vol. 20 No. 1, pp. 19-28.

Madhill, H. et al (2003), "Making Choices and Making Transitions - Creating A Web Resource", Proceedings of the GASAT 11 International Conference, Mauritius, 6-11 $1^{\text {th }}$ July 2003.

Moore, D. and Buttner, E.H. (1997), Women Entrepreneurs: Moving beyond the glass ceiling, Sage, London.

QAA (2001), Code of Practice: Career education, Information and Guidance, available at www.qaa.ac.uk/academicinfrastrusture/codeOfPractice/section8/default.asp

Powell, A., Bagilhole, B., Dainty, A. and Neale, R. (2004), "Does the Engineering Culture in UK Higher Education Advance Women's Careers?", Equal Opportunities International, Vol 23 No 7, pp21-38. 
Rae, D. (2005), “Mid-career entrepreneurial learning”, Education + Training, Vol. 47 No. $8 / 9$, pp. $652-574$.

Rae, D. (2007), “Connecting enterprise and graduate employability. Challenges to the higher education culture and curriculum?", Education + Training, Vol. 49 No. 8/9, pp. 605-619.

Russell, M., Haritos, G. and Combes, A. (2006), “Individualising students' scores using blind and holistic peer assessment", Engineering education, Vol. 1 No. 1, pp. 5060 .

Setwomenstats.org.uk (UK Resource for women in Science, Engineering and Technology) 2004/5, www.setwomenstats.org.uk

Srivastava, A. (1996), "Widening Access: Women in Construction Higher Education", PhD thesis, Leeds Metropolitan University.

The Daily Telegraph $6^{\text {th }}$ September 1995.

Times Higher Education $6^{\text {th }}$ March 2008

Yasin, M., Czuchry, A., Martin, J., Feagins, R. (2000), “An open systems approach to higher learning: the role of joint ventures with business", Industrial Management \& Data Systems, 100/5, pp 227-233. 